der retroversio-flexio Uteri, \&c." (Centralbl. für Gynäk., 1888, Bd. xii., s. 17,34 , and 102 , with figures; and 1885 , Bd. ix., s. 664). 3. Howard Kelly: "Hysterorrhaphy," with figures (Amer. Journ. Obstet., 1887, vol. xx., p. 33). 4. Klotz: Centralbl. fiur Gynäk., 1888, Bd. xii., s. 11, 69. 5. Leopold : "Ueber die Annähung der retroflektiren Gebärmutter an der vorderen Bauchwand" (Centralbl. für Gynäh. 1888, Bd. xii., s. 161).

\section{A CASE OF \\ ACUTE DELIRIOUS MANIA COMPLICATED WITH STRANGULATED HERNIA AND WITH ABNORMAL TEMPERATURES.}

\section{BY FREDERICK BRYAN, M.B.,}

ASSISTANT MEDICAL OFFICER, COLNEY HATCH LUNATIC ASYLUM.

G. L_, aged sixty-five, labourer, was admitted to Colney Hatch Asylum on Nov. 10th, 1887, when the following notes were made. The patient is a tall, well-developed man, somewhat feeble and shaky, but able to stand. Heart and lungs healthy. He has very rigid and tortuous arteries. He has a right inguinal hernia, which is somewhat hard. There is no impulse on coughing. Owing to his mental state, no history of any kind can be obtained from him. Mentally, he is in a state of acute delirious mania. He is incoherent, and shouts out loudly; he pays no attention to questions whatever. Tongue clean. Pulse full and strong. Pupils equal, and react normally. Knee reflexes are normal and equal. He was sent to bed.

Nov. 11th.-Reported very restless and noisy during the night. Has been wet, but had no action of the bowels. An attempt to reduce the hernia failed. Evening temperature $97^{\circ}$. Ordered twenty grains of chloral hydrate.

12th. - This morning at 11 o'clock, fifty-seven hours after admission, after some slight hiccoughing, he vomited once; the vomit was distinctly fæcal. Pulse good; tongue clean. One hour afterwards he underwent the usual operation for strangulated hernia, the taxis having failed. No difficulty was experienced during the operation. The sac was not opened. Immediately on his return to bed, he passed a very copious loose motion. A morphia suppository (one-third of a grain) was administered. Evening temperature $99^{\circ}$.

13th.-Morning temperature $99^{\circ}$; evening $100^{\circ}$. Very restless and maniacal during the night. $\mathrm{He}$ had removed part of the dressings. Wound dressed. Pulse good. Tongue clean. Has had some milk and beef-tea.

14th. - Still very maniacal and restless. Wet and dirty during the night. Some urine was caught and examined: sp. gr. 1025 ; acid ; no albumen; high-coloured. Evening temperature $99^{\circ}$. Ordered twenty grains of chloral hydrate

15th. - Temperature normal to-day. Wound dressed. Owing to his restlessness the stitches had given way, and the edges were brought together with strapping. It looks healthy.

16th.-Wet and dirty during the night. Wound dressed; healing from the bottom. Takes his food well. Very restless and maniacal. Is tied in bed. Temperature normal. (No further interest was attached to his hernia; it gave rise to no adverse symptoms, and was practically well at the date of his death.)

17th. - There is no change in his maniacal symptoms. There is little loss of strength. He takes his food well, but it is noticed that there is a little difficulty in swallowing. From to-dlay his temperature runs rather a remarkable course, as seen by the following table:-

\begin{tabular}{|c|c|c|c|c|c|}
\hline \multicolumn{2}{|c|}{ Nov. 17th } & & A.M. & & $\begin{array}{l}\text { P.M. } \\
97 \cdot 6^{\circ}\end{array}$ \\
\hline & 18th & & $96 \cdot 0^{\circ}$ & & $970^{\circ}$ \\
\hline & 19th & $\cdots$ & $97 \cdot 0^{\circ}$ & & $97 \cdot 1^{\circ}$ \\
\hline , & 20 th & & $97^{\circ} 0^{\circ}$ & & $96 \cdot 1^{\circ}$ \\
\hline , & $21 \mathrm{st}$ & & $95 \cdot 6^{\circ}$ & & $97 \cdot 3^{\circ}$ \\
\hline & $22 \mathrm{nd}$ & & $98 \cdot 0^{\circ}$ & & $98 \cdot 2^{\circ}$ \\
\hline
\end{tabular}

On the morning of the $23 \mathrm{rd}$ he was reported to have been seized with a fit of trembling, and apparently to have lost power in his left leg. One hour later, when examined, he bad distinct loss of expression on the right side of his face.
There was then no other paralysis. His pupils were equal and reacted to light. His knee reflexes were exaggerated, and the stimulus used to demonstrate this produced spasm in the thigh nuscles. Well-marked ankle clonus. There was some hyperæsthesia in both legs below the knee. The difficulty in swallowing had increased. Temperature: morning, $102^{\circ}$; evening, $98^{\circ} 2^{\circ}$. The subsequent tempera. tures were as follows :-

\begin{tabular}{|c|c|c|c|c|}
\hline \multirow{2}{*}{ Nov. 24th } & & & & \\
\hline & 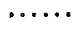 & $100 \cdot 2^{\circ}$ & ...... & $100 \cdot 6^{\circ}$ \\
\hline 20 th & $\ldots \ldots$ & $102 \cdot 0^{\circ}$ & ….. & $101 \cdot 6^{\circ}$ \\
\hline 26 th & ….. & $101 \cdot 0^{\circ}$ & ...... & $\begin{array}{l}101 \cdot 6^{\circ} \\
101 \cdot 4^{\circ}\end{array}$ \\
\hline 28 th & ?..... & $101 \cdot 7^{\circ}$ & $\begin{array}{l}\cdots \cdots . . \\
\ldots . . .\end{array}$ & $\begin{array}{l}\text { Lo } \\
102 \cdot 0^{\circ}\end{array}$ \\
\hline 29th & & $101 \cdot 6^{\circ}$ & & $1060^{\circ}$ at 7 \\
\hline
\end{tabular}

After this his temperature was taken every quarter of an hour. It rose gradually from $106^{\circ}$ to its naximum of $108^{\circ}$, when death ensued. Half an hour after death the temperature was $104^{\circ}$, and then slowly fell. During the last twelve hours the patient had been in a state of stupor. His pulse was full and strong. He breathed rather laboriously. His eyes were closed, but when opened the conjunctivæ were sensitive to touch, and the pupils reacted to light.

Shortly before his death some friends visited him and gave the following history. From boyhood the patient was noticed to have been somewhat stupid and eccentric, but he had always been well employed. At times he had drunk hard. About five months ago they had noticed him become very strange, and he did odd things and was restless. Particularly they noticed that he became wet and dirty. A month before admission he was suddenly dismissed from his situation, and after a short period of depression became maniacal and was removed to the parish infirmary. As far as his friends knew, there was no family history of insanity.

Necropsy.-In the rightinguinal region there was a superficial granulating wound, the remains of the wound made in relieving his stranoulated hernia. There was no other sign of external injury or disease. Lungs hypostatically congested, otherwise normal. Heart somewhat enlarged, dne to some general dilatation; valves healthy; aorta very atheromatous. Abdominal organs healthy. There was no sign of peritonitis. Although carefully looked for, the seat of the strangulation of the gut could not be found. On examination of the head the calvaria was found to be normal; the dura mater was also normal. On removal of the brain a small quantity of fluid escaped. The arteries at the base of the brain were rigid and atheromatous. The pia mater at the base of the brain was little changed. That on its upper surface was gelatinous in appearance and much thickened. There were no adhesions between it and the cortex, but it peeled off as if gummed to the cortex. It was removed nearly as a whole, and when held up to the light was opaque and crowded with large vessels. The gelatinous appearance of the pia mater was apparently partly caused by the presence of serous fluid in its meshes. It was tough, and its thickness many times that of normal. The cortex was somewhat greasy to the finger. No other sign of disease was discovered in the brain. The ventricles were of normal capacity, and contained no fluid. There was no sign of any hæmorrhages or softening. The cord was removed and examined. Its membranes were healthy, and there was no sign of disease to the naked eye on section.

Remarlss.-Surgically, this case is interesting from the scarcity of symptoms pointing to strangulation. Although it appeared that there was no impulse in the hernia on cougling, still this was somewhat uncertain owing to the difficulty of making the patient cough well. Practically, the only symptom was the vomiting; and this occurred only once, and was frecal, fifty-six hours after admission. This abeyance of symptoms is met with in lunacy practice, often to a very great degree; and the writer knows of at least one other case in which there were no symptoms produced by a strangulated hernia. Medically, the case was looked upon as an acute attack, superimposed upon a chronic disease of the membranes of the brain. In nearly all cases of acute delirious mania a sudden shock is the assigned cause; in this case the patient's sudrlen dismissal from his situation appears to have been the exciting cause of his acute deliriun. The abnormal temperature was very interesting. Abnormally high temperatures, and, (?) less frequently, abnormally low temperatures, are fairly common in the insane, but as far as I know the combination is unusual. Whilst watching the progress of this case it 
occurred to me that itwould be very instructive to endeavour to explain the possible cause of the abnormal temperature. The usual explanation of elevation of temperature is, to put it shortly, increased tissue metabolism, and the cause of low temperature exactly the reverse. In this case, how ever, it appears to me that this explanation does nothold good, as the condition of the patient-viz., that of exaggerated restlessness and delirium--was the same during the period of low as during the period of high temperature, at any rate as far as the elevation to $104^{\circ}$. The possible explanation appeared to be that the so-called "heat-regulating" centre in the cortex had been directly interfesed with by the disease of its membranes, and this case seems at least to suggest some corroboration of the presence of this cortical centre. That the thickened, gelatinous membranes must have affected the functions of the subjacent cortex cannot, I think, be doubted; and the fact of the facial paralysis and the evanescent limb paralysis a common feature in general paralysis of the insane, in which the naked-eye appearances of the membranes are exactly as in this case-I think corroborates this.

For permission to publish this case I am indebted to Dr. Seward, medical superintendent of the male department. Colney Hatch.

\section{PERFORATION DURING ENTERIC FEVER; RELAPSE ; RECOVERY.}

\section{BY RICHARD LAKE, L.R.C.P. LOND., \&e.}

ON March 28th last I was called in to see a young lady, aged nineteen, suffering from sickness and diarrhoea. She gave the following account of herself. Twenty-five days previously she was seized with romiting and diarrhoea during the night; the latter continued until four days before the above date, when she complained of more malaise than hitherto, and was given a saline purge. All her previous troubles now became exaggerated, and troublesome vomiting set in.

On examination her abdomen was slightly distended and tumid. Pain was present in the right iliac fossa, also gurgling. No spots were found. The vonit was clear and of a bright-green colour. The stools were of a vellow peasoupr consistence, with some floating flakes of mucus; fifteen stools during the last twenty-four hours. Temperature $103^{\circ}$; pulse 100 . Tongue red in centre; edges covered with a thick white fur; dry, but not cracked.

March 29th.-Bowels acted thirteen times during the day. Less vomiting. Liver duIness increased, with marked tenderness over the whole organ. Ice given to suck.

30th.-No vomiting until 5 P.M. One-third of a grain of morphia was given thrice in six hours to check the diarrhœea.

The temperature from the 28 th for five days fluctuated between $103^{\circ}$ and $101^{\circ} \mathrm{F}$., being only slightly influenced by antifebrin. The symptoms scarcely varied at all, excepting that the diarrhoea was checked by the three doses of morphia. During the next five days defervescence took place, the morning fall approaching or reaching normal, and the evening rise only once reaching $101^{\circ}$. During the four following days the chart was about this level, the temperature rising once to $1025^{\circ}$; this was due to constipation, as the temperature fell inmediately the bowels acted. (See chart.) On the night of April 9th pain was complained of in the abdomen, but was not severe, and was treated as colic by hot fomentations. As the pain continued and became more severe, the temperature rising, the patient at the same time getting an anxious expression, the abdomen was subjected to another examination, with the result of the discovery of a tender spot midway between the eighth right costal cartilage and the umbilicus. The hot fomentations were reapplied and nourishment given, chiefly brandy and raw beef juice. At mid-day on the 10th, the fall of temperature was so sudden, and symptoms of collapse so rapidly followed, the face becoming blanched, the tongue dry, and the pulse frequent and small, that perforation of the intestine was diagnosed, which belief was strengthened by the persistence of tenderness in the right hypochondrium, together with some ill-defined dulness there, with sharp shooting pain in the abdomen. Hot bottles were used to pack the patient in, and the following measures taken to endeavour to prolong life. The patient was kept in the dorsal decubitus, with Hexed legs and thighs, together with the application of hot fomentations to the abdomen. Of this period a chart is given, continued until all signs of inflammatory action had ceased-i.e., on April 14th. An ounce of brandy, with an ounce of raw beef juice, were given in the form of an enema every hour; also five minims of tincture of opium every hour by the mouth for the time the patient remsined awake, and then every two hours until the l2th; subsequently every four hours until the 14th, when it was discontinued entirely, and food again administered by the mouth. With regard to the general and local symptoms after the morning of the $11 \mathrm{th}$, green vomiting was again present, but was checked by sucking ice. The dulness in the right hypochondrium extended until it occupied an area of about four inches in diameter, forming a fairly well-defined

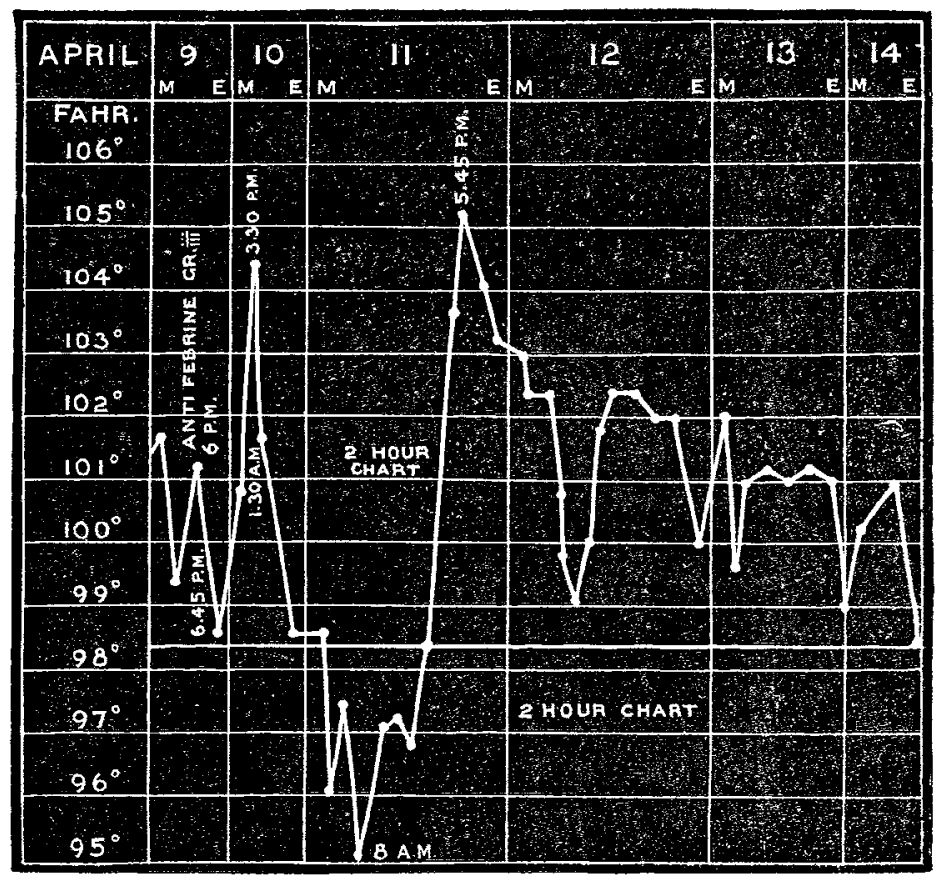

tumour, very painful on palpation ; this began to contract on the 14th, was almost imperceptible on the $28 \mathrm{th}$, and was entirely absent by the 10th of May. The pain was at all times the same, sharp and lancinating, and often accompanied by vomiting. The bowels were only moved by glycerine enemata, and there was much chalky matter in the motions. The breath was exceedingly offensive, and had a strong frecal odour. From the 14th to the 18th the temperature remained subnormal, with evening rises above the normal. On the latter day a relapse commenced, the temperature reaching $102 \cdot 6^{\circ}$ on the evening of the $22 \mathrm{nd}$, falling to the normal by the 27 th. There was one rise on the 26th up to $104 \cdot 2^{\circ}$, with voniting; this was explained by the bowels not having acted, as on the $7 \mathrm{th}$. The patient has lately returned to Scotland, and is quite well to all appearances.

Remarlis.-Any doubt remaining as to this case being enteric ferer is remover by the following facts. 1. The patient contracted the illness in a district where enteric was prevalent. 2. The main and house drains were very defective, the former blocked, as I learn from the medical officer of health for the town. 3. Several other pupils from the same house had the disease; the date of invasion being in all cases the same, and three deaths occurring, one of those first mentioned being under my care suffering from enteric. 4: Nurse Scarman, to whose skilful care the successful issue of the case was largely due, contracted enteric, and was treated at the Victoria Nursing Home, from which institution she came. The chief interest of the case lies in the period expressed on the chart-i. e., from April 9th to the 14th. It is obvious that some severe lesion had occurred on the evening of the 9th, as is shown by the sudden collapse and rapid rise of temperature which followed. Ur. Donald Hood has recorded several cases of venous thrombosis in the course of enteric fever, which have suggested perforation by their course and symptoms; but though collapse may be present in these cases, neither is the fall so low as $95^{\circ}$, nor is the rise afterwards so high. It is known that perforation may occur in a portion of the intestine bound down by Q 2 